Check for updates

Cite this: RSC Adv., 2019, 9, 9845

\title{
Alkyl coupling in tertiary amines as analog of Guerbet condensation reaction $\dagger$
}

\author{
Yage Zhou, ab Dan Wu, ț $^{\mathrm{b}}$ Willinton Yesid Hernández, ${ }^{\mathrm{b}}$ Changru Ma, ${ }^{\mathrm{b}}$ Huangyang Su ${ }^{\mathrm{ab}}$ \\ and Vitaly Ordomsky (ID *b
}

Received 8th October 2018

Accepted 5th March 2019

We report here that $\mathrm{C}-\mathrm{C}$ coupling in tertiary amines for the synthesis of long chain and hindered amines might be efficiently performed over Pt and Pd catalysts. The mechanism study confirms similarity with the Guerbet reaction through dehydrogenation of the alkyl group and subsequent attack of the $\alpha$ carbon atom by an alkyl group of another molecule. Finally, secondary amines and tertiary amines with longer alkyl chains are formed.

rsc.li/rsc-advances

Tertiary amines are important products in the modern chemical industry. Usually applications of tertiary amines include quaternary derivatives, amine oxides and betaines which are used in household, industrial, and institutional cleaners and disinfectants, wood treatment, personal care, oil field, and water treatment end-use markets. ${ }^{1}$

Different methods have been reported for the synthesis of tertiary amines, for example, (1) reductive alkylation of aldehydes with secondary amines over metal catalysts, ${ }^{2}$ (2) N-alkylation of amines or nitroarenes with alkylhalides or alcohols, ${ }^{3}$ (3) hydroamination of olefins with amines ${ }^{4}$ and (4) amination of arylhalides. ${ }^{5}$ The main disadvantage of these routes is complex multistep processes and environmental pollution due to the usage of aggressive chemicals like halides. At the same time, these methods often provide low selectivities to desired tertiary amines.

There are several classes of tertiary amines, which are especially important. The linear tertiary amines containing alkyl chain between 6 and 20 carbon atoms with two other short chain alkyl or piperidine ring are the commonly referred to fatty tertiary amines which are used for the synthesis of surfactants. ${ }^{6}$ Hindered tertiary amines containing iso-alkyl groups is another important class of tertiary amines which is hard to produce. ${ }^{7}$ These amines are used as a non-nucleophilic base and as a stabilizer for polymers. ${ }^{8}$

The problem of increase of the chain length for alcohols and synthesis of isomerized alcohols have been solved by Marcel

\footnotetext{
${ }^{a}$ State Key Laboratory of Chemical Engineering, School of Chemical Engineering, East China University of Science and Technology, 130 Mei Long Road, Shanghai 200237, China

${ }^{b}$ Eco-Efficient Products and Processes Laboratory (E2P2L), UMI 3464 CNRS-Solvay, 201108 Shanghai, People's Republic of China. E-mail: vitaly.ordomsky-ext@solvay.com $\dagger$ Electronic supplementary information (ESI) available: Methods, metal surface area, TEA, TPA and $N$-ethylpiperidine transformation, TEM. See DOI: 10.1039/c8ra08316a

\$ Equal contribution to first author.
}

Guerbet in 1899. ${ }^{9}$ The Guerbet reaction involves coupling of two (or more) alcohol molecules through intermediate aldehyde formation, aldol condensation, dehydration of aldol product and hydrogenation of allylic aldehyde. The reaction proceed over bifunctional catalysts containing usually $\mathrm{Cu}, \mathrm{Ni}$ metal for dehydrogenation/hydrogenation and base sites like $\mathrm{MgO}$ for $\mathrm{C}-\mathrm{H}$ bond activation and coupling reaction. ${ }^{10}$

Depending on the types of used alcohols in the reaction like long chain or short chain branched or unbranched products could be formed, respectively. ${ }^{11}$ This route would be an interesting opportunity for the synthesis of long chain or hindered amines. We have found that transformation of tertiary amines over Pd and Pt metallic catalyst proceed through C-C coupling with formation of heavier amines depending on the type of used tertiary amine.

The transformation of non-symmetric tertiary amines over Pd black has been described in 1978 by Murahashi et al. ${ }^{12}$ The authors observed fast exchange of alkyls with formation of the mixture of tertiary amines. The reaction has been explained by insertion of palladium into a carbon-hydrogen bond adjacent to the nitrogen, leading to a highly active intermediate complex of an iminium ion. Afterwards a lot of reports have been devoted to C-C coupling of tertiary amines with different compounds like acrylates ${ }^{13}$ and alkynes ${ }^{14}$ usually activated by electro and photo-energy. ${ }^{15}$ The self-alkylation of triethylamine over noble metal catalysts in $\mathrm{CO}$ atmosphere has been described in the patent, ${ }^{16}$ however, no mechanism or further applications have been proposed. As far as we know, there are no scientific studies devoted to $\mathrm{C}-\mathrm{C}$ coupling between tertiary amines. The reaction proceed by transfer of alkyl group from one molecule to another with formation of new $\mathrm{C}-\mathrm{C}$ bond and increase of the chain length in one tertiary amine and formation of secondary amine from another molecule (Fig. 1).

Triethylamine (TEA) has been chosen as a model reagent for the reaction like ethanol in Guerbet reaction. Table 1 demonstrates catalytic performance of different noble metallic 

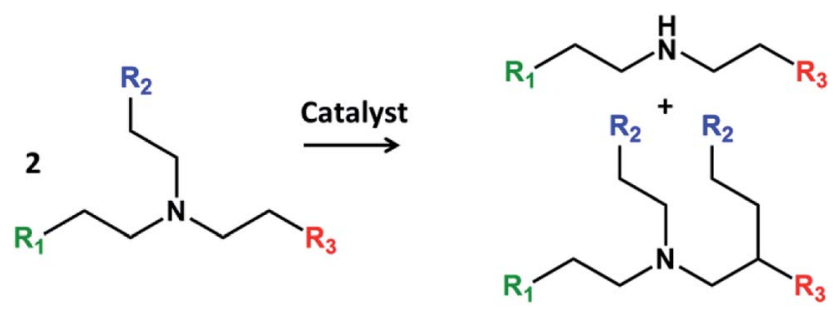

Fig. 1 Scheme of alkyl coupling of tertiary amines.

Table 1 Catalytic results of transformation of TEA over different catalysts ( $2 \mathrm{~g}$ TEA, $p\left(\mathrm{~N}_{2}\right)=5$ bar, $0.1 \mathrm{~g}$ catalyst, $0.24 \mathrm{~mol} \% \mathrm{Pd}, 5 \mathrm{~h}$ )

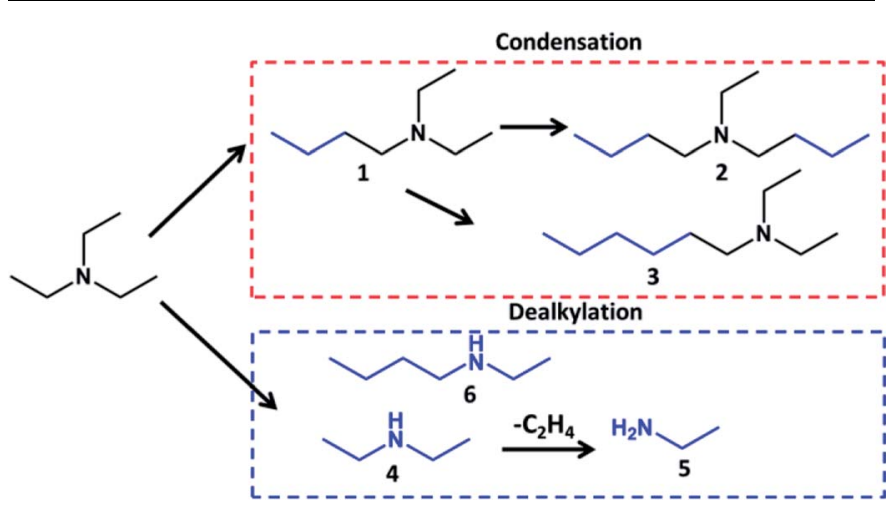

Selectivity to amines, mol\%

$\underline{\text { Coupling Dealkylation }}$

\begin{tabular}{|c|c|c|c|c|c|c|c|c|c|}
\hline Catalyst & $T,{ }^{\circ} \mathrm{C}$ & TOF, $\mathrm{h}^{-1}$ & Conv.,\% & 1 & 2 & 3 & 4 & 5 & 6 \\
\hline - & 200 & - & 1 & - & - & - & - & - & - \\
\hline $\mathrm{Pd} / \mathrm{C}$ & 200 & 622 & 89 & 20 & 13 & 3 & 26 & 11 & 17 \\
\hline $\mathrm{Pt} / \mathrm{C}$ & 200 & 400 & 62 & 27 & 5 & 3 & 44 & 12 & 8 \\
\hline $\mathrm{Pd} / \mathrm{Al}_{2} \mathrm{O}_{3}$ & 200 & 164 & 47 & 41 & 5 & 1 & 42 & 9 & 2 \\
\hline $\mathrm{Pd} / \mathrm{Al}_{2} \mathrm{O}_{3}{ }^{a}$ & 200 & 94 & 27 & 39 & 2 & - & 42 & 11 & - \\
\hline $\mathrm{Pd} / \mathrm{Al}_{2} \mathrm{O}_{3}{ }^{b}$ & 200 & 128 & 37 & 47 & 2 & - & 48 & 3 & - \\
\hline $\mathrm{Pd} / \mathrm{Al}_{2} \mathrm{O}_{3}{ }^{c}$ & 200 & 83 & 24 & 44 & 4 & - & 49 & 1 & - \\
\hline $\mathrm{Ru} / \mathrm{Al}_{2} \mathrm{O}_{3}$ & 200 & 14 & 3 & 48 & - & - & 49 & - & - \\
\hline $\mathrm{Ru} / \mathrm{C}$ & 200 & 25 & 13 & 38 & 1 & 4 & 55 & 2 & 2 \\
\hline $\mathrm{Rh} / \mathrm{Al}_{2} \mathrm{O}_{3}$ & 200 & - & 2 & - & - & - & - & - & - \\
\hline $\mathrm{Pd} / \mathrm{Al}_{2} \mathrm{O}_{3}$ & 150 & 13 & 4 & 43 & - & - & 53 & - & 2 \\
\hline $\mathrm{Pd} / \mathrm{Al}_{2} \mathrm{O}_{3}$ & 250 & - & 88 & 14 & 7 & 4 & 30 & 26 & 11 \\
\hline Pd black & 200 & 6 & 8 & 47 & - & - & 43 & - & - \\
\hline $\mathrm{Ni} / \mathrm{Al}_{2} \mathrm{O}_{3}$ & 200 & 62 & 16 & 51 & 4 & 3 & 44 & - & - \\
\hline
\end{tabular}

${ }^{a} \mathrm{H}_{2}$ gas phase. ${ }^{b}$ Cyclohexane has been used as a solvent. ${ }^{c} \mathrm{~N}_{2}$ pressure was 30 bar.

catalysts containing $5 \mathrm{wt} \%$ of the metal over carbon and alumina supports during transformation of TEA in batch reactor at $150-250{ }^{\circ} \mathrm{C}$. The main reaction products might be subdivided into two groups: tertiary amines of condensation and secondary amines of dealkylation reactions. The main condensation products in the liquid phase involve butyldiethylamine, dibutylethylamine, hexyldiethylamine. The dealkylation products contain diethylamine, ethylamine and butylethylamine. The identification and assignment of the products by GC-MS and NMR is given in the Fig. S1-S5, ESI. $\dagger$
The catalytic activity in transformation of TEA in inert atmosphere depends on the type of the metal, dispersion and support. The catalysts have been characterized by TEM and CO adsorption to determine the metal surface area (Table S1, Fig. S6-S7, ESI $\dagger$ ). TOF numbers over the same supports decrease in the row $\mathrm{Pd}>\mathrm{Pt}>\mathrm{Ni}>\mathrm{Ru} \approx \mathrm{Rh}$. It should be noted that activity is higher over carbon support in comparison with alumina. This catalytic behaviour correlates with activity of the metals in hydrogenation/dehydrogenation reactions. Indeed, $\mathrm{Pt}$, Pd and Ni are well known as highly active hydrogenation catalysts in comparison with $\mathrm{Rh}$ and Ru which are good catalysts for hydrogenolysis reactions. ${ }^{17}$ This is why amination of aldehydes or alcohols over Pt and Pd lead to the synthesis of secondary and tertiary amines and $\mathrm{Rh}$ and $\mathrm{Ru}$ to selective synthesis of primary amines..$^{18}$ It has to be noted that Pd black provides very low activity in transformation of TEA, which indicates on size, and electronic effect of Pd nanoparticles on intrinsic activity of TEA transformation. It explains mainly exchange activity of this catalyst in tertiary amines reported in the work of Murahashi. ${ }^{12}$

Analysis of the dependence of the selectivity versus conversion over $\mathrm{Pd} / \mathrm{Al}_{2} \mathrm{O}_{3}$ shows that selectivity to butyldiethylamine and diethylamine is close to $50 \%$ at low conversion and decreases with increase of the conversion (Fig. 2). The selectivity to the heavier products like dibutylethylamine and hexyldiethylamine is increasing with increase of the conversion. At the same time, we observe appearance of new dealkylation products like ethylamine, butylethylamine and dibutylamine. Thus, reaction takes consecutive character with transformation of initially formed butyldiethylamine further into the heavier products. The selective disproportionation to butyldiethylamine and diethylamine at reasonable conversion might be attained using organic solvent (Table 1). Indeed, inert solvent isolates the product from further reaction and improves the selectivity.

This distribution of the products could be explained by combination of condensation and decomposition reactions of tertiary amines. However, analysis of the gas phase during transformation of TEA at the reaction conditions $\left(200^{\circ} \mathrm{C}\right)$ shows absence of hydrocarbons which means that reaction does not

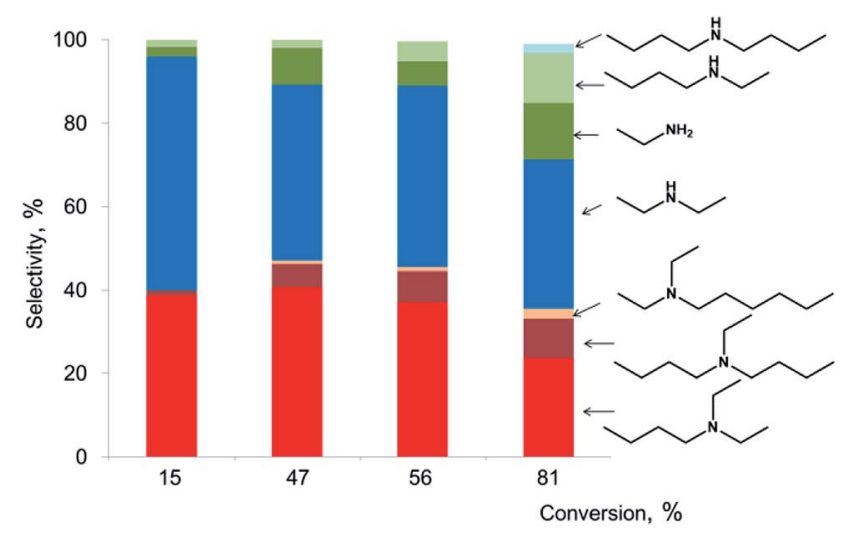

Fig. 2 Selectivity to the products of TEA transformation depending on the conversion of TEA over $\mathrm{Pd} / \mathrm{Al}_{2} \mathrm{O}_{3}(5 \mathrm{wt} \%)$ catalyst $\left(T=200{ }^{\circ} \mathrm{C}, 2 \mathrm{~g}\right.$ TEA, $p\left(\mathrm{~N}_{2}\right)=5$ bar, $0.1 \mathrm{~g}$ catalyst, $\left.0.24 \mathrm{~mol} \% \mathrm{Pd}, 1-17 \mathrm{~h}\right)$. 
proceed through dealkylation of tertiary amines and most probably takes place by direct transfer of alkyl group from one tertiary amine to another one. Also carbon balance analysis shows that the molar amount of tertiary amines multiplied by amount of added $\mathrm{C}_{2}$ units corresponds to amount of amines with lost ethyl groups (Table S2, ESI †).

The key parameters for the reaction have been found to be reaction temperature and gas phase. At $150{ }^{\circ} \mathrm{C}$ there is almost no conversion of TEA (Table 1). Increase of the temperature to 200 and $250{ }^{\circ} \mathrm{C}$ resulted in increase of the conversion to 47 and $88 \%$, respectively. Higher temperature resulted in significant increase of the contribution of heavy (dibutylethylamine, hexyldiethylamine) and light amines (ethylamine, ethylbutylamine). The dealkylation with formation of ethylene starts to take place only at high temperature $\left(250^{\circ} \mathrm{C}\right)$, which explains increase of the selectivity to ethylamine (Table 1 ).

In the presence of hydrogen in the reactor activity was significantly lower which indicates that reaction is probably related to dehydrogenation activity of the catalyst (Table 1). Dehydrogenation activity of the catalyst might be easily controlled by pressure in the reactor. Increase of the pressure leads to suppression of the dehydrogenation activity but results in the higher selectivity to butyldiethylamine and diethylamine (Table 1).

Guerbet reaction gives linear alcohols only during transformation of ethanol. Longer chain alcohols participate in condensation with formation of isomerized alcohols due to easier activation of $\mathrm{C}-\mathrm{H}$ bond in $\mathrm{CH}_{2}$ groups. ${ }^{10}$ In order to verify that this rule works for tertiary amines we have performed reaction of transformation of tri- $n$-propylamine (TPA). The main product of the reaction over $\mathrm{Pd} / \mathrm{Al}_{2} \mathrm{O}_{3}$ in comparison with TEA was tertiary amine with isomerized alkyl chain - 2-methyl- $N, N$ dipropylpentane-1-amine (Table 2) with only traces of linear hexyldipropylamine (Table S3, ESI $\dagger$ ). The identification and assignment of the products by GC-MS and NMR is given in the Fig. S8-S11, ESI. $\dagger$ It indicates that propyl group attaches to the secondary $\beta$ carbon atom of propyl group of another tertiary amine. In the case of TEA it leads to the synthesis of linear butyl chain.

The activity of TPA transformation was lower in comparison with TEA most probably due to steric restrictions in the

Table 2 Catalytic results of transformation of TPA over $\mathrm{Pd} / \mathrm{Al}_{2} \mathrm{O}_{3}$ (5 wt\%) (2 g TPA, $p\left(\mathrm{~N}_{2}\right)=5$ bar, $0.1 \mathrm{~g}$ catalyst, $0.34 \mathrm{~mol} \% \mathrm{Pd}, 5 \mathrm{~h}$ )

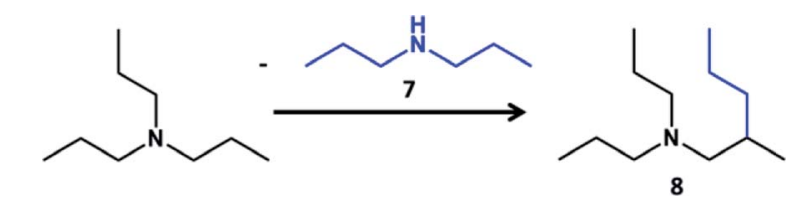

Selectivity to amines, $\mathrm{mol} \%$

\begin{tabular}{lllll} 
Catalyst & $T,{ }^{\circ} \mathrm{C}$ & Conv., $\%$ & 7 & 8 \\
\hline $\mathrm{Pd} / \mathrm{Al}_{2} \mathrm{O}_{3}$ & 200 & 9 & 54 & 44 \\
$\mathrm{Pd} / \mathrm{Al}_{2} \mathrm{O}_{3}$ & 250 & 69 & 62 & 30
\end{tabular}

condensation of alkyl groups. It has to be noted that stability of TPA toward decomposition at $250{ }^{\circ} \mathrm{C}$ was lower than for TEA which resulted in appearance of light hydrocarbons (propane, hexane) and increase of the contribution of dipropylamine and propylamine (Tables 2 and S3, ESI $\dagger$ ).

One of the main disadvantages of this route of the synthesis of tertiary amines is that at high conversion reaction does not proceed in the direction of increase of only one alkyl chain. All groups of tertiary amine participate in the condensation. The possible solution of this problem could be in transformation of tertiary amines containing only one active group for coupling reaction. The alkyl groups might be not active in the coupling reaction, for example, when the role of two alkyls is playing aliphatic ring like in the case of $N$-ethylpiperidine (Table 3). The main products of the reaction are tertiary amines with selective growth of ethyl toward long chain alkyl group (Table S4, ESI†). The identification and assignment of the products by GC-MS is given in the Fig. S12-S13, ESI. $\dagger^{\dagger}$

The mechanism of the reaction of $\mathrm{C}-\mathrm{C}$ coupling in tertiary amines has been studied by FTIR spectroscopy. Fig. 3 demonstrates results of adsorption of TEA over $\mathrm{Pd} / \mathrm{Al}_{2} \mathrm{O}_{3}$ with subsequent heating. Adsorbed TEA demonstrates usual set of bands attributed to asymmetric and symmetric $\mathrm{C}-\mathrm{H}$ stretching in $\mathrm{CH}_{2}$ and $\mathrm{CH}_{3}$ groups $\left(2972,2882\right.$ and 2940, $\left.2827 \mathrm{~cm}^{-1}\right), \mathrm{CH}_{2}$ and $\mathrm{CH}_{3}$ bending (1460 and $1385 \mathrm{~cm}^{-1}$ ) and $\mathrm{C}-\mathrm{N}$ stretching $\left(1206 \mathrm{~cm}^{-1}\right)$ vibrations. Gradual heating to $100{ }^{\circ} \mathrm{C}$ results in appearance of the band at $1580 \mathrm{~cm}^{-1}$ assigned to olefin double bond with significant decrease of the bands related to $\mathrm{CH}_{3}$ groups. Thus, the first step is dehydrogenation of TEA to enamines on the metal surface (Fig. 4). Enamine-imine tautomerization should lead to negative charge of terminal $\mathrm{CH}_{2}{ }^{-}$ group and double $\mathrm{C}=\mathrm{N}$ bond which explains disappearance of $\mathrm{C}-\mathrm{N}$ stretching. The formation of palladium-iminium complex has been identified earlier. ${ }^{19,20}$

Further heating of the sample to $200{ }^{\circ} \mathrm{C}$ leads to appearance of the new bands at 1643 and $1530 \mathrm{~cm}^{-1}$ which might be explained by formation of conjugated double bonds in smaller

Table 3 Catalytic results of transformation of $\mathrm{N}$-ethylpiperidine over $\mathrm{Pd} / \mathrm{Al}_{2} \mathrm{O}_{3}$ (5 wt\%) (2 g N-ethylpiperidine, $p\left(\mathrm{~N}_{2}\right)=5 \mathrm{bar}, 0.1 \mathrm{~g}$ catalyst, $0.27 \mathrm{~mol} \% \mathrm{Pd}, 5 \mathrm{~h})$

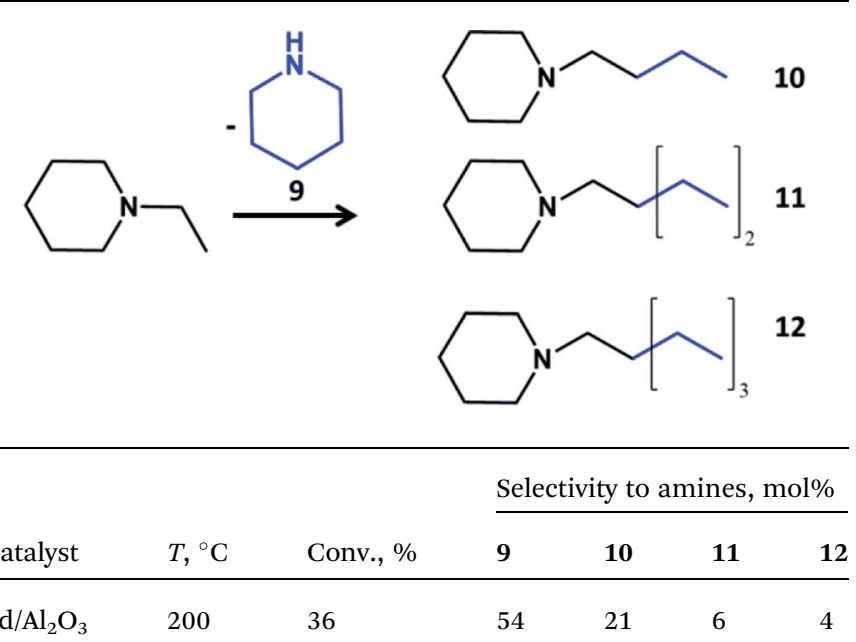



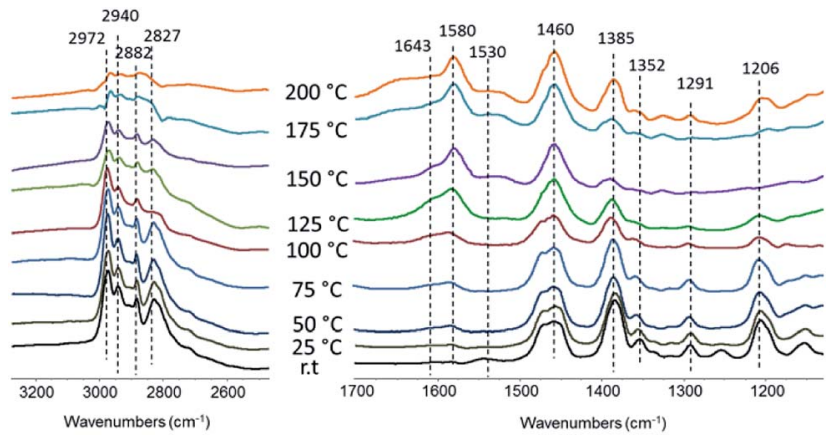

Fig. 3 FTIR spectra during transformation of TEA over $\mathrm{Pd} / \mathrm{Al}_{2} \mathrm{O}_{3}$.
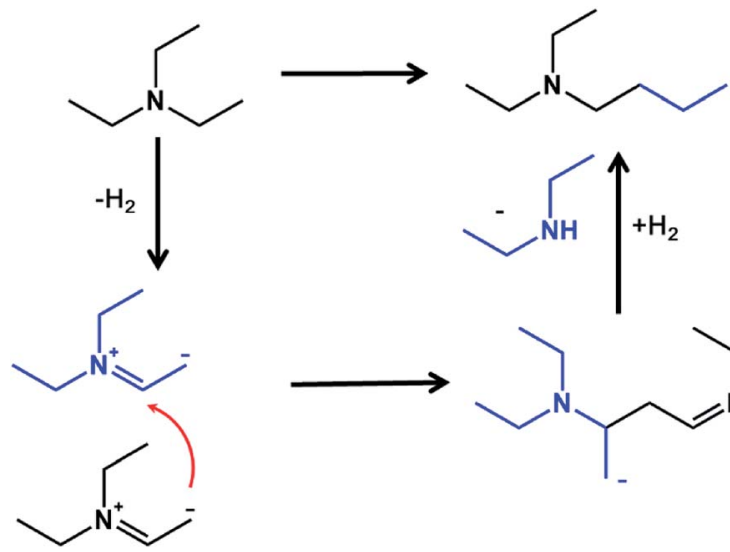

Fig. 4 Scheme of the mechanism of the reaction.

molecules. Enamines are well known as strong nucleophiles and have been used earlier in the reactions of alkylation, acylation etc. ${ }^{21}$ Similar to Guerbet condensation mechanism it should lead to attack of $\alpha$-carbon attached to nitrogen by $\mathrm{CH}_{2}{ }^{-}$ with formation of C-C bond (Fig. 4). The bond of $\mathrm{N}$ with tertiary carbon should not be stable and splits with removal of secondary amine like water in Guerbet condensation. In infrared cell at low pressure these amines will be in dehydrogenated state which leads to appearance of high frequency $\mathrm{C}=\mathrm{C}$ group vibration. In the reactor subsequent hydrogenation of the formed product should result in the formation of butyldiethylamine and diethylamine as the main products of the reaction (Fig. 4).

The formation of intermediate diamine compounds from TEA could be observed during analysis of the reaction kinetic by ${ }^{13} \mathrm{C}$ and ${ }^{1} \mathrm{H}$ NMR. The presence of weak signals of protons shifted down-field due to higher electronic density in $-\mathrm{CH}_{2}-$ groups and signal of carbon shifted high-field due to presence of tertiary carbon indicates on the presence of diamine compounds in the reaction products (Fig. S3 and S4, ESI $\dagger$ ). The NMR analysis also shows presence of traces of olefins with ${ }^{1} \mathrm{H}$ shift 7 and $3.6 \mathrm{ppm}$ in the product of the reaction which indicates on hydrogen borrowing mechanism of the reactions (Fig. S5, ESI†). GC-MS analysis also shows the presence of additional peak at high retention time, which according to MS spectrum, might be assigned to diamine compound (Fig. S1 and $\mathrm{S} 2, \mathrm{ESI} \dagger)$.
The stability of intermediate diamine product should be higher in the case of delocalization of nitrogen electrons into the pi system of the benzene ring. In order to prove formation of intermediate diamine species, $N, N$-diethylaniline has been converted over $\mathrm{Pd} / \mathrm{Al}_{2} \mathrm{O}_{3}$ catalyst (Table 4). $\mathrm{N}$-Butyl- $N$-ethylaniline and $\mathrm{N}$-ethylaniline are the main products of coupling and dealkylation at $53 \%$ conversion, respectively. Additionally $6 \%$ of diamine has been observed in the products by attack of $\alpha$ carbon atom of ethyl group of one molecule by $\beta$-carbon atom of ethyl group of another molecule. The identification and assignment of the products by GC-MS is given in the Fig. S14S15, ESI. $\dagger$

Usually Guerbet reaction requires besides metal also acid or base sites for condensation of aldehydes by activation of $\mathrm{C}-\mathrm{H}$ bond. ${ }^{10,11}$ In the case of tertiary amines condensation proceed even over carbon support (Table 1) which means that it might take place directly over metal surface. The interaction of formed enamine species with metal surface through $\mathrm{Pd}-\mathrm{N}$ bond could shift equilibrium to imine and promote coupling reaction. In order to check the state of metal during reaction of TEA we have added $\mathrm{CO}$ at room temperature after reaction of TEA at $200{ }^{\circ} \mathrm{C}$.

Fig. 5 demonstrates results of $\mathrm{CO}$ adsorption over parent $\mathrm{Pd} /$ $\mathrm{Al}_{2} \mathrm{O}_{3}$ catalyst. The peaks at $2090 \mathrm{~cm}^{-1}$ and $1977 \mathrm{~cm}^{-1}$ with shoulder at $1920 \mathrm{~cm}^{-1}$ are observed which might be assigned to linear and bridged bonded CO, respectively. ${ }^{22}$ The presence of TEA and products on the surface of metal leads to significant broadening of the $\mathrm{CO}$ peaks and shift to the lower frequencies. This result indicates on broad distribution of electronic states of Pd and higher electronic density on the metal leading to transfer from d-orbital of the metal to anti-bonding orbital of $\mathrm{CO}^{23}$

The imine form of adsorbed dehydrogenated TEA is highly polarized molecule and should interact strongly with $\mathrm{Pd}$ through double bond $\mathrm{C}=\mathrm{N}$ and $\mathrm{CH}_{2}{ }^{-}$group (Fig. 5). The fact that the highest activity is observed over small size supported metal nanoparticles might be explained by strong stabilization of imine over defected Pd sites which provides high activity in the coupling reaction.

Table 4 Catalytic results of transformation of $\mathrm{N}, \mathrm{N}$-diethylaniline over $\mathrm{Pd} / \mathrm{Al}_{2} \mathrm{O}_{3}$ (5 wt\%) (2 g N,N-diethylaniline, $p\left(\mathrm{~N}_{2}\right)=5 \mathrm{bar}, 0.1 \mathrm{~g}$ catalyst, $0.36 \mathrm{~mol} \% \mathrm{Pd}, 5 \mathrm{~h})$

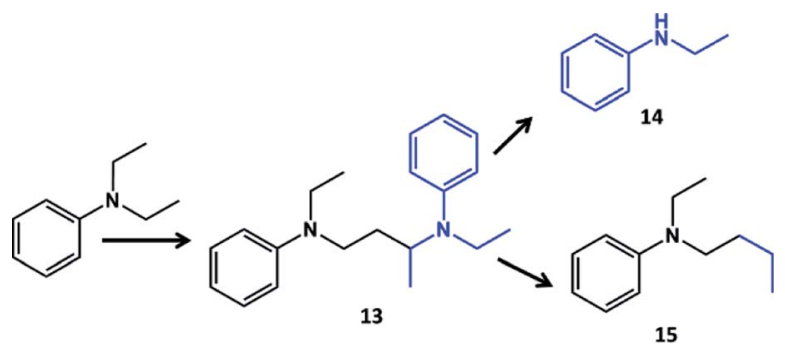

Selectivity to amines, $\mathrm{mol} \%$

\begin{tabular}{llllll} 
Catalyst & $T,{ }^{\circ} \mathrm{C}$ & Conv., \% & $\mathbf{1 3}$ & $\mathbf{1 4}$ & $\mathbf{1 5}$ \\
\hline $\mathrm{Pd} / \mathrm{Al}_{2} \mathrm{O}_{3}$ & 200 & 53 & 6 & 48 & 32
\end{tabular}




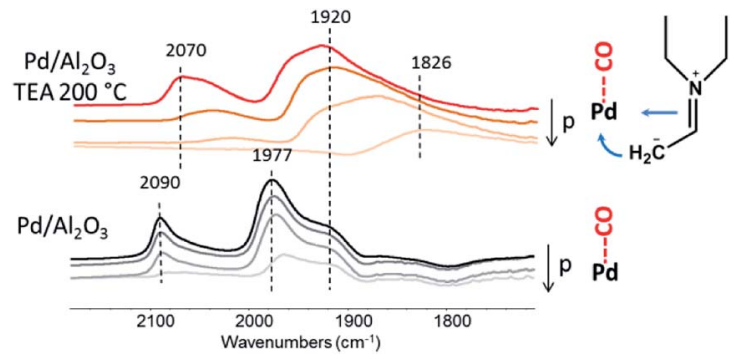

Fig. 5 FTIR CO adsorption with desorption in vacuum over $\mathrm{Pd} / \mathrm{Al}_{2} \mathrm{O}_{3}$ before and after treatment of TEA.

To conclude, we uncovered that tertiary amines in the presence of Pd and Pt catalysts can transfer alkyl groups by $\mathrm{C}-\mathrm{C}$ coupling with formation of tertiary amines with longer chains and secondary amines. The proposed mechanism based on FTIR results is similar to Guerbet condensation reaction and involves dehydrogenation with subsequent attack of $\alpha$-carbon atom by carbanion with elimination of secondary amine. This method provides tool for the synthesis of long chain or hindered tertiary amines.

\section{Conflicts of interest}

There are no conflicts to declare.

\section{Notes and references}

1 J. Brunet and D. Neibecker, Catalytic Heterofunctionalization from Hydroamination to Hydrozirconation, ed. A.Togni and H.Grützmacher, VCH, Weinheim, Germany, 2001, pp 91141.

2 R. O. Hutchins and M. K. Hutchins, in Comprehensive Organic Synthesis, ed. B. M.Trost and I.Fleming, Pergamon Press, New York, 1991, vol. 8, pp 25-78.

3 T. E. Muller and M. Beller, Chem. Rev., 1998, 98, 675-704.

4 T. E. Müller, K. C. Hultzsch, M. Yus, F. Foubelo and M. Tada, Chem. Rev., 2008, 108(9), 3795-3892.

5 Y. Aubin, C. Fischmeister, C. M. Thomas and J.-L. Renaud, Chem. Soc. Rev., 2010, 39, 4130-4145.
6 K. Visek, Kirk-Othmer Encyclopedia of Chemical Technology, 2003, pp. 518-533.

7 C. Ainsworth and R. N. Easton, J. Org. Chem., 1961, 26(10), 3776-3779.

8 N. Z. Yagafarov, P. N. Kolesnikov, D. L. Usanov, V. V. Novikov, Y. V. Nelyubina and D. Chusov, Chem. Commun., 2016, 52, 1397-1400.

9 M. Guerbet and C. R. Acad, . Sci. Paris, 1899, 128, 511.

10 J. T. Kozlowski and R. J. Davis, ACS Catal., 2013, 3, 15881600.

11 D. Gabriëls, W. Y. Hernández, B. Sels, P. Van Der Voort and A. Verberckmoes, Catal. Sci. Technol., 2015, 5, 3876-3902.

12 S.-I. Murahashi, T. Hirano and T. Yano, J. Am. Chem. Soc., 1978, 100, 348-350.

13 X. Dai, D. Cheng, B. Guan, W. Mao, X. Xu and X. Li, J. Org. Chem., 2014, 79(15), 7212-7219.

14 F. Alonso, A. Arroyo, I. Martín-García and Y. Moglie, Adv. Synth. Catal., 2016, 16, 3549-3561.

15 T. Zhang, W. Liang, Y. Huang, X. Li, Y. Liu, B. Yang, C. He, X. Zhoua and J. Zhang, Chem. Commun., 2017, 53, 1253612539.

16 K. H. Chao, Alkylation of amine compounds, US Pat. 4845295, 1987.

17 W. Zang, G. Li, L. Wang and X. Zhang, Catal. Sci. Technol., 2015, 5, 2532-2553.

18 J. Bódis, L. Lefferts, T. E. Müller, R. Pestman and J. A. Lercher, Catal. Lett., 2005, 104, 23-28.

19 E.-U. R. McCrindle, G. Ferguson, G. J. Arsenault and A. J. McAlees, Chem. Commun., 1983, 571-572.

20 F. R. S. Clark, R. O. C. Norman and C. B. Thomas, J. Chem. Soc., Perkin Trans. 1, 1975, 121-125.

21 G. Stork, A. Brizzolara, H. Landesman, J. Szmuszkovicz and R. Terrell, J. Am. Chem. Soc., 1963, 85(2), 207-222.

22 H. Tiznado, S. Fuentes and F. Zaera, Langmuir, 2004, 20, 10490-10497.

23 S. Bertarione, D. Scarano, A. Zecchina, V. Johánek, J. Hoffmann, S. Schauermann, M. M. Frank, J. Libuda, G. Rupprechter and H.-J. Freund, J. Phys. Chem. B, 2007, 108(11), 3603-3613. 